\title{
Parent's Use and Likely Utilization of Nutrition Education Resources in the Mississippi Delta Region
}

\author{
Rachel Scoggins, ${ }^{1, *}$ Laurel Lambert, ${ }^{2}$ and Kathy Knight ${ }^{2}$

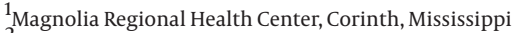 \\ ${ }^{2}$ The University of Mississippi, Mississippi, United States \\ *Corresponding author: Rachel Scoggins, Magnolia Regional Health Center, 611 Alcorn Drive, MS 38834, Corinth, Mississippi. Tel: +662-2931194, E-mail: racheljcampbell@gmail.com
}

Received 2015 June 7; Revised 2015 August 7; Accepted 2015 August 10.

\begin{abstract}
Background: Parental involvement has been identified as one of the most important factors affecting children's health. There has been limited investigation on nutrition education resources preferred by parents living in the Mississippi Delta, a region of the state with the highest rates for poverty and diet-related diseases. Understanding what type of nutrition education resources are currently used by parents and what type of resources parents would likely use, if made available, will be beneficial to health educators in developing and disseminating nutrition education resources and facilitate the greatest impact.

Objective: Identifying nutrition education resources used by parents.

Patients and Methods: Low-income parents of elementary school-aged children were surveyed on their 'current use' and 'likely use' of nutrition education resources. Survey packets were delivered to teachers in three elementary schools who then distributed the surveys to their students to deliver to their parents. Completed surveys were returned to the teacher who delivered them to the researchers. Descriptive statistics were used to summarize responses.

Results: The most common nutrition education resources currently used by parents are nutrition facts labels $(\mathrm{m}=3.58 \pm \mathrm{SD} 1.31)$, television shows ( $\mathrm{m}=3.24 \pm \mathrm{SD} 1.12)$, and healthy homework activities from their child's school $(\mathrm{m}=3.18 \pm \mathrm{SD} 1.40)$. Resources seldom used by parents are video games $(\mathrm{m}=1.49 \pm \mathrm{SD} 0.87$ ), healthy cooking classes $(\mathrm{m}=1.76 \pm \mathrm{SD} 1.03)$, and online discussion boards $(\mathrm{m}=1.75 \pm \mathrm{SD} 1.01)$. The nutrition education resources parents would likely use are healthy homework activities $(\mathrm{m}=4.21 \pm \mathrm{SD} 0.95)$ and information sent home from school $(\mathrm{m}=4.15 \pm$ SD 0.94). Parents reported they would least likely use video games ( $\mathrm{m}=1.95 \pm$ SD 1.31), online discussion boards ( $\mathrm{m}$ $=2.47 \pm \mathrm{SD} 1.34$ ), and mobile phone applications ( $\mathrm{m}=2.69 \pm \mathrm{SD} 1.42)$.

Conclusions: Identifying nutrition education resources currently being used and most likely to be used by parents will be beneficial to health educators when developing and implementing effective nutrition interventions with parents in the Mississippi Delta and other rural regions.
\end{abstract}

Keywords: Low-Income Population, Parents, Education, Nutrition Survey

\section{Background}

The residents of the Mississippi Delta(Delta), a geographical region in Mississippi, have the highest rates in the nation for diet-related diseases such as obesity, hypertension, and diabetes (1). This region also has the highest poverty rate in the state (2). Researchers reported that in the Mississippi Delta, African American households, with children living at home and yearly incomes below $\$ 15,000$, have significantly higher rates of food insecurity compared to national averages (3). Food insecurity, defined as lack of consistent access to nutritional and adequate food obtained in socially acceptable ways (4), has been linked to poor diet quality and childhood obesity (5), diet quality of families living in the Delta is of concern because foods available within the home impact children's eating habits (3).

The home food environment is created through interaction between the parent, the child, and food within the home. The food environment and meals prepared for the family are influenced by the parent's nutrition knowledge, food preferences, finances, and time constraints (6, 7). With nutrition knowledge and self-efficacy to prepare healthful meals, parents are able to provide a healthier food environment (7). Research has shown that lack of health knowledge and financial barriers negatively impact the degree to which parents are involved in their child's healthy eating $(8,9)$. The Delta population has been identified as having low health literacy, creating a challenging environment which disseminates health and nutrition related information (10).

Zoellner et al. found that television, newspapers, magazines, and internet were effective methods for delivering nutrition information to adults, living in the Delta (10). However, they trusted information obtained from television more than from the internet. As a healthcare provider, physicians were also seen as a trusted source of health in-

Copyright ( 2016, Shiraz University of Medical Sciences. This is an open-access article distributed under the terms of the Creative Commons Attribution-NonCommercial 4.0 International License (http://creativecommons.org/licenses/by-nc/4.0/) which permits copy and redistribute the material just in noncommercial usages, provided the original work is properly cited. 
formation (10). In fact, health care providers (physicians, nutritionists, and nurses) have been shown to be effective mediators of health information by either directly providing information or implementing educational programs for health improvement among diverse populations (11-15).

The school system can also serve as a mediator in delivering nutrition education resources to parents. The Healthy, Hunger-Free Kids Act of 2010 (16) requires all schools participating in federal meal programs to have a school wellness policy in place. This policy requires nutrition education components that should involve students, teachers, and parents (16). Nutrition education programs targeting parents have yielded positive results. Although there has been limited investigation on nutrition education resources and delivery modes preferred by parents in the Delta (10), school-based programs with a family component have shown improved healthy lifestyle in parents and their children $(17,18)$.

\section{Objectives}

Understanding what type of nutrition education resources are currently used by parents and what type of resources parents would likely use, if made available, will be beneficial to health educators in developing and disseminating nutrition education resources and facilitate the greatest impact.

\section{Patients and Methods}

Parents or guardians of students in grades kindergarten through 2nd were solicited from a convenient sample of three public elementary schools in three Delta counties. All three schools in the sample reported $98 \%$ or greater student eligibility for free and reduced-price meals, allowing researchers access to a low-income parent population. This study was approved by the institutional review board at the researchers' affiliated institution.

A survey was used to collect data on low-income parents' 'current use' and 'likely use,' if made available, of nutrition education resources. Survey questions were developed through a literature review and with the assistance of experts in the fields of nutrition and education, who evaluated the survey for clarity and inclusiveness. The pilot survey was then given to six parents of elementary school children who also evaluated the survey for clarity of instruction, readability, terminology, and content of items.

The survey included two items addressing importance to the parent of their child eating healthy and current and likely use of 14 different nutrition education resources (Table 1) using a 5-point Likert-type scale from 5 (very important) to 1 (not at all important). The next section addressed how often parents received nutrition education resources from five mediators (school nutrition directors, teachers, nurses, nutritionists, and physicians), using a 3-point Likert-type scale from 3 (frequently) to1 (never). Parents were also asked which mediator they would prefer, using a ranking system of 1 (most preferred) to 5 (least preferred). The third section solicited demographic information: education, age, gender, and race. Internal reliability scales were $\alpha=0.85$ (currently used nutrition education resources) and $\alpha=0.93$ (likely to be used nutrition education resources) which are in the ranges of acceptable internal consistency ( $\alpha \geq 0.7)$ (19).

Table 1. Paired T-Test of Current Use and Likely Use of Nutrition Education Resources $(\mathrm{n}=214)$

\begin{tabular}{|c|c|c|c|}
\hline Resource & Values $^{\mathrm{a}}$ & $\mathbf{t}$ & PValue \\
\hline $\begin{array}{l}\text { Information sent home with your child } \\
\text { from school }\end{array}$ & & 12.60 & .00 \\
\hline Currently use & $3.00(1.31)$ & & \\
\hline Likely to use & $4.15(0.94)$ & & \\
\hline $\begin{array}{l}\text { Healthy homework activities sent home } \\
\text { with your child from school }\end{array}$ & & -0.43 & .00 \\
\hline Currently use & $3.18(1.40)$ & & \\
\hline Likely to use & $4.21(.95)$ & & \\
\hline Television shows & & -2.66 & .01 \\
\hline Currently use & $3.24(1.12)$ & & \\
\hline Likely to use & $3.45(1.22)$ & & \\
\hline Magazines & & -3.31 & .00 \\
\hline Currently use & $3.05(1.11)$ & & \\
\hline Likely to use & $3.31(1.26)$ & & \\
\hline Healthy eating online websites & & -4.18 & .00 \\
\hline Currently use & $2.77(1.28)$ & & \\
\hline Likely to use & $3.11(1.42)$ & & \\
\hline Online meal planner & & -9.62 & .00 \\
\hline Currently use & $2.07(1.15)$ & & \\
\hline Likely to use & $2.95(1.43)$ & & \\
\hline $\begin{array}{l}\text { Tips from friends on Facebook, Twitter, } \\
\text { or Pinterest }\end{array}$ & & -5.58 & .00 \\
\hline Currently use & $2.41(1.32)$ & & \\
\hline Likely to use & $2.81(1.41)$ & & \\
\hline Mobile phone applications (apps) & & -7.17 & .00 \\
\hline Currently use & $2.10(1.24)$ & & \\
\hline Likely to use & $2.69(1.42)$ & & \\
\hline Online discussion or message boards & & -9.20 & .00 \\
\hline Currently use & $1.75(1.01)$ & & \\
\hline Likely to use & $2.47(1.34)$ & & \\
\hline Healthy eating or cooking class online & & 10.42 & .00 \\
\hline Currently use & $1.84(1.06)$ & & \\
\hline Likely to use & $2.76(1.49)$ & & \\
\hline $\begin{array}{l}\text { Healthy eating or cooking class in- } \\
\text { person }\end{array}$ & & 12.35 & .00 \\
\hline Currently use & $1.76(1.03)$ & & \\
\hline Likely to use & $3.05(1.51)$ & & \\
\hline Grocery store tours & & -8.43 & .00 \\
\hline Currently use & $2.49(1.47)$ & & \\
\hline Likely to use & $3.25(1.52)$ & & \\
\hline Video games & & -6.02 & .00 \\
\hline Currently use & $1.49(0.87)$ & & \\
\hline Likely to use & $1.95(1.31)$ & & \\
\hline Nutrition facts label on food packaging & & -5.52 & .00 \\
\hline Currently use & $3.58(1.31)$ & & \\
\hline Likely to use & $4.03(1.27)$ & & \\
\hline
\end{tabular}


In October 2013, survey packets were delivered to teachers in grades kindergarten through 2 nd in all three participating schools. Packets included instructions for survey distribution, parent surveys, and small toys as incentives for students whose parents completed the survey. The teachers distributed surveys to their students to deliver to their parents who were then given 10 days to complete and return surveys to the teacher who delivered them to the researchers. The method design has been shown to be reliable when surveying parents of elementary school children (20).

Descriptive statistics of means, standard deviations, and frequencies were used to summarize responses. Paired t-tests were used to identify significant differences between current use and likely use of nutrition education resources for the 14 items. An ANOVA and LSD post-hoc tests were conducted to evaluate how parent responses for current use and likely use of nutrition education resources varied by education, age, gender, and race. All statistical analyses were performed using SPSS version 21 (SPSS Inc., Chicago, IL, 2012).

\section{Results}

A total of 319 of 586 (54\%) parents returned the surveys. Due to incomplete responses, 105 surveys were excluded, resulting in 214 of 586 (37\%) surveys used for analyses (Table 2). The majority of parents were African American (88\%), female (92\%), and ages 25 to 34 (59\%), with high school/GED (29\%), some college education (31\%), and 2-year college degrees (18\%).

\subsection{Importance of Healthy Eating and Mediators}

The majority of parents (92\%) responded that it is very important that their child eats healthy and $87 \%$ responded that they do provide healthy meals to their children. Parents stated that they presently receive nutrition information "sometimes" to "frequently" from a physician (70\%), a nutritionist (55\%), a nurse (49\%), their child's school nutrition director (43\%), and their child's teacher (40\%). However, $53 \%$ of parents ranked nutritionists as the most preferred choice for receiving nutrition information, with physicians ranked as the second preferred (32\%), and school nutrition director ranked as third (24\%). The nurse and child's teacher were fourth and fifth at $12 \%$ and $7 \%$, respectively. Percentages total greater than $100 \%$ due to some parents ranking more than one mediator which they preferred.

\subsection{Current Use and Likely Use of Nutrition Education Resources}

The nutrition education resources that parents most frequently use are nutrition facts labels $(\mathrm{m}=3.58 \pm \mathrm{SD}$ 1.31), television shows ( $m=3.24 \pm$ SD 1.12), and healthy homework activities from their child's school $(\mathrm{m}=3.18 \pm$ SD 1.40),(Table 1). Resources seldom or rarely used by parents are video games $(\mathrm{m}=1.49 \pm 0.87)$, in-person healthy cooking classes $(m=1.76 \pm S D 1.03)$, and online discussion boards $(\mathrm{m}=1.75 \pm \mathrm{SD} 1.01)$.
Table 2. Demographic Characteristics of Participating Parents (N = 214), Mississippi Delta Region

\begin{tabular}{|c|c|}
\hline Demographic Characteristics & Values $^{\mathrm{a}}$ \\
\hline \multicolumn{2}{|l|}{ Education } \\
\hline Less than high school & $9(4.2)$ \\
\hline High school or GED & $61(28.5)$ \\
\hline Some college & $66(30.8)$ \\
\hline 2-year associate degree & $39(18.2)$ \\
\hline 4-year bachelor's degree & $19(8.9)$ \\
\hline Greater than bachelor's degree & $20(9.3)$ \\
\hline \multicolumn{2}{|l|}{ Age, y } \\
\hline $18-24$ & $19(8.9)$ \\
\hline $25-34$ & $127(59.3)$ \\
\hline $35-44$ & $40(18.7)$ \\
\hline $45-54$ & $20(9.3)$ \\
\hline $55-64$ & $8(3.7)$ \\
\hline Over 64 & 0 \\
\hline \multicolumn{2}{|l|}{ Gender } \\
\hline Male & $17(7.9)$ \\
\hline Female & $197(92.1)$ \\
\hline \multicolumn{2}{|l|}{ Ethnicity } \\
\hline Native American & $3(1.4)$ \\
\hline Asian & $1(0.5)$ \\
\hline African American & $188(87.9)$ \\
\hline Hispanic & $2(0.9)$ \\
\hline Caucasian & $16(7.5)$ \\
\hline Pacific Islander & $2(0.9)$ \\
\hline Other & $2(0.9)$ \\
\hline
\end{tabular}

${ }^{\mathrm{a}}$ Data are presented as No. (\%).

The nutrition education resources parents would most likely use are healthy homework activities $(\mathrm{m}=4.21 \pm \mathrm{SD}$ .95) and other healthy eating information sent home from school ( $\mathrm{m}=4.15 \pm$ SD 0.94), and nutrition facts labels $(\mathrm{m}=4.03 \pm S D 1.27)$. Parents reported they would least likely use video games ( $\mathrm{m}=1.95 \pm \mathrm{SD} 1.31)$, online discussion boards ( $\mathrm{m}=2.47 \pm \mathrm{SD} 1.34)$, and mobile phone applications $(\mathrm{m}=2.69 \pm \mathrm{SD} 1.42)$.

Paired t-tests showed positive statistical differences (P $\leq 0.01$ ) between the current use and likely use of the 14 nutrition education resources (Table 1). An ANOVA indicated statistical significance between education level for current use of healthy eating websites, $\mathrm{F}(5,208)=3.46, \mathrm{P}$ $<0.01$, and healthy eating tips from friends on Facebook, Twitter, or Pinterest (social media), $\mathrm{F}(5,208)=2.93, \mathrm{P}=$ 0.01. The LSD post-hoc tests are shown in Table 3. 
Scoggins R et al.

Table 3. Analysis of variance Between Currently Used Nutrition Education Resources and Educational Level ${ }^{\mathrm{a}}$

\begin{tabular}{lcccccc}
\hline $\begin{array}{l}\text { Nutrition } \\
\text { Education Resource }\end{array}$ & $\begin{array}{c}\text { Less Than High } \\
\text { School }\end{array}$ & $\begin{array}{c}\text { High School } \\
\text { or GED }\end{array}$ & $\begin{array}{c}\text { Some } \\
\text { College }\end{array}$ & $\begin{array}{c}\text { Two Year } \\
\text { Associate Degree }\end{array}$ & $\begin{array}{c}\text { Fouryear } \\
\text { Bachelor's Degree }\end{array}$ & $\begin{array}{c}\text { Greater Than } \\
\text { Bachelor's Degree }\end{array}$ \\
\hline $\begin{array}{l}\text { Healthy eating } \\
\text { online resources }\end{array}$ & $2.56 \pm 1.74$ & $2.28 \pm 1.20^{\mathrm{b}}$ & $2.93 \pm 1.21^{\mathrm{b}}$ & $2.98 \pm 1.14^{\mathrm{b}}$ & $2.74 \pm 1.28$ & $3.40 \pm 1.35^{\mathrm{b}}$ \\
$\begin{array}{l}\text { Tips from friends } \\
\text { on Facebook, }\end{array}$ & $2.11 \pm 1.05$ & $2.07 \pm 1.33^{\mathrm{b}}$ & $2.63 \pm 1.27^{\mathrm{b}}$ & $2.64 \pm 1.37^{\mathrm{b}}$ & $1.84 \pm 0.89$ & $2.90 \pm 1.48^{\mathrm{b}}$ \\
\begin{tabular}{l} 
Twitter, or Pinterest \\
\hline
\end{tabular} & & & & & & \\
\hline
\end{tabular}

${ }^{\mathrm{a}}$ Data are presented as mean $\pm \mathrm{SD}$.

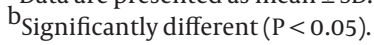

\section{Discussion}

\subsection{Importance of Healthy Eating and Mediators}

Consistent with two previous studies $(9,21)$, parents in this study believe healthy eating within the context of their family environment is important and show interest in nutrition and healthy eating for their children. Parents also reported that physicians are the primary mediator for delivering nutrition information which supports previous research in which physicians and other health care providers were found to be the most trusted resource to receive nutrition-related information among television, family and friends, magazine, newspaper, radio, and internet (10).

Nutritionists were identified by parents as the second most common source for receiving nutrition information. In 2014, there were 87,937 participants in the Mississippi women, infants, and children (WIC) supplemental food program, whose charge was to provide nutrition counseling. It may be likely that parents in this study received nutrition information from nutritionists with this program (22). This study did not determine if parents were WIC participants, the extent of interaction with nutritionists, or the type of information received from a nutritionist.

Another nutrition assistance program available to lowincome families is the supplemental nutrition assistance program (SNAP). The congressional district encompassing the Delta had 63,925 households receiving SNAP benefits according to 2015 SNAP participation report (23). Parents not participating in WIC could be supplied with nutrition education through SNAP.

The third preferred mediator was school nutrition directors. While this study did not obtain educational backgrounds, it has been shown that schools having directors who are also nutritionists increases the likelihood of their participation in federal nutrition initiatives (24). School nutrition directors can be valuable mediators in sending nutrition information home with students such as monthly menus, healthy eating suggestions, and food preparation tips. Directors have reported a lack of nutrition education resources for parents (25). However, websites such as Team Nutrition are valuable resources for nutrition education materials (26).
Only $7 \%$ of parents identified their child's teacher as a preferred mediator. However, parents reported nutrition information and activities sent home from school as frequently used resources. In this context, these resources are provided by another mediator or it is likely that parents are not making the connection between the teacher and nutrition information. Previous research findings have determined that connecting with parents and involving them in school-related nutrition education programs is successful in improving diet quality among families $(27,28)$.

\subsection{Current Use and Likely Use of Nutrition Education Resources}

The top nutrition education resources currently used by Delta parents are nutrition facts labels, television, and homework activities (Table 1). Katz et al. showed that homework on how to read food labels increased parents' nutrition label reading literacy $(27,28)$.

This study did not establish the subject matter of the nutrition education resources currently used by parents, so it cannot be ascertained if parents have received information on reading nutrition facts labels from their child's school. Previous research has found that parents with higher nutrition knowledge are more likely to use nutrition facts labels (29). While $60 \%$ of parents in this study had greater education than high school level, the extent of their nutrition knowledge was not measured. However, it has been reported that the Delta population has low health knowledge (10).

Television shows were the second most frequent nutrition education resource currently being used by parents. Previous findings showed that the Delta adult population trusted television as a health education resource (10). With numerous food and cooking television channels available it is not surprising that this would be a popular resource. Further research is necessary to determine the credibility of nutrition information made available through television.

Healthy homework activities and information sent home from school were among the top five resources currently being used and likely to be used by parents. Health-related activities completed as homework, pre- 
mised on parent-child cooperation, has been effective in improving children's health (17). Homework aimed at improving the home health environment may be advantageous, especially if parents are already receptive to these resources.

It has been reported that low-income populations use internet accessed sites such as discussions boards for seeking health information (30). Also, use of social networking sites was found to be successful in recruiting low-income women for nutrition education (31). However, in this study, three of the five least used, and four of the five least likely to be used nutrition education resources, required internet or wireless access. Parents living in the Delta may lack access or means to use online resources. While online resources have been successfully used for improving nutrition knowledge and behavior $(20,32)$ and cited as an acceptable alternative to traditional education programs (33), this study showed that online nutrition education resources may not be suitable or well received by parents in the Delta.

Mobile phone applications (apps) were not likely to be used by parents as a source of nutrition information in this study. Although, apps have been viewed as an acceptable education tool (34), researchers have identified that nutrition education apps were not reliable sources of accurate information (35). It is necessary to ensure mobile apps is a valid and reliable information to be used by nutrition educators.

Parents reported that currently they rarely or seldom use in-person healthy cooking classes (mean $=1.8, \mathrm{SD} \pm$ 1.0). However, it appears that parents may want to have this resource (mean $=3.1, \mathrm{SD} \pm 1.5$ ). In-person healthy cooking classes could be a welcomed opportunity for nutritionists or school nutrition directors to interact with parents with the goal of increasing healthy eating in the family. Successful participation may be dependent on providing child care during classes and means of transportation in this parent population (36).

Currently, video games are the least used and the least likely to be used nutrition education resource by parents. This may be unfortunate since nutrition education video games have been shown to positively change diet behavior and are adaptable to diverse populations (32).

As limitations, this study addressed the use of nutrition education resources by a small convenient sample of parents living in counties located in the northern half of the Mississippi Delta region. These results may not reflect other areas of the Delta or other populations who differ in geographical location, demographics, and culture. While the survey covered an extensive list of nutrition education resources, other methods such as focus groups may be beneficial in obtaining additional nutrition education resources used by this population. Another challenge was percentage rate of returned surveys. Due to incomplete surveys many had to be excluded from analysis. This could be due to survey length, unclear instructions, or lack of importance placed on completing the survey and may have resulted in selection bias.

The study's findings highlight key areas for nutrition educators to target in developing intervention programs. While previous research reported adults in the Mississippi Delta preferred the internet in receiving health information $(10,33)$, this study found that parents preferred more traditional delivery modes of nutrition education through nutrition information and homework activities sent home with their children from school. Schools can be a tremendous conduit in communicating with all parents of elementary school children in efforts to deliver nutrition education information.

Second to physicians, parents most often receive their nutrition education from nutritionists, who were identified as the preferred mediator. Access to specialty healthcare professionals is oftentimes limited in rural areas (37). This is especially true with nutritionists, who are prevented from seeking employment in these regions due to financial and job opportunity barriers (38). Since relationships between nutritionists and parents have been established, additional routes should be explored where nutritionists can make contact with this population.

An unexpected finding was that parents identified teachers as the least preferred mediators who provide little nutrition information. However, they reported frequently using healthy homework activities sent home from their child's school. The role of teachers as main mediators in communicating health messages needs to be further explored because of their role in creating positive relationships with parents and affecting parental involvement with the school environment (39).

School nutrition directors, the third preferred mediator, can serve as a tremendous resource of nutrition education materials for parents. Because of their role in the management of federally supported meal programs they are more likely aware of nutrition education resources accessed through various government sites. It would be worthwhile to investigate how school nutrition directors could establish a stronger relationship with parents in efforts to maximize their influence as a preferred mediator. These efforts should also be made in collaboration with teachers and other school professionals to send a consistent message.

In efforts to address obesity and improve nutrition in the Mississippi Delta population it is important to realize that parents play a key role in the type of foods purchased and meals prepared within the home. With appropriate and accessible nutrition education resources, parents can be better equipped to provide healthy food environments for their children. The findings of this study will be valuable to nutrition educators who help parents improve their health and the health of their families.

\section{Acknowledgments}

The authors thank the school principals for granting permission for their schools' participation, the school staff for distributing and collecting the surveys, and Yun- 
hee Chang Ph.D., Associate Professor of the nutrition and hospitality management department at the University of Mississippi, for providing guidance in statistical analysis and her insightful feedback.

\section{Footnote}

Authors' Contribution:Rachel Scoggins developed the study concept and design. Acquisition of data was provided by Rachel Scoggins and Laurel Lambert. Drafting and critical revision of the manuscript and statistical analysis are provided by Rachel Scoggins, Laurel Lambert, and Kathy Knight. Material support is provided by Kathy Knight. In addition, This study was supervised by Laurel Lambert.

\section{References}

1. Lower Mississippi Delta Nutrition Intervention Research C. Selfreported health of residents of the Mississippi Delta. J Health Care Poor Underserved. 2004;15(4):645-62. [PubMed: 15531821]

2. United States Department of Agriculture. Food and Nutrition Service, Office of Policy Support. Profile of SNAP households. 2015. Available from: http:|/www.fns.usda.gov/sites/default/files/ops/ Mississippi_2.pdf.

3. Stuff JE, Horton JA, Bogle ML, Connell C, Ryan D, Zaghloul S, et al. High prevalence of food insecurity and hunger in households in the rural Lower Mississippi Delta. J Rural Health. 2004;20(2):17380. [PubMed: 15085632$]$

4. Life Sciences Research Office. Core indicators of nutritional state for difficulty to sample populations.. 1990.

5. Kaiser LL, Townsend MS. Food insecurity among US children: Implications for nutrition and health. Topic Clin Nutr. 2005;20(4):313-20.

6. Holsten JE, Deatrick JA, Kumanyika S, Pinto-Martin J, Compher CW. Children's food choice process in the home environment A qualitative descriptive study. Appetite. 2012;58(1):64-73. doi: 10.1016/j.appet.2011.09.002. [PubMed: 21986183]

7. Marks R, Prelip M, Le Thai C, Toller Erausquin J, Slusser W. Improving low income parents' fruit and vegetable intake and their potential to impact children's nutrition. Health Educ. 2011;111(5):391411. doi:10.1108/09654281111161220.

8. Crawford D, Timperio A, Campbell K, Hume C, Jackson M, Carver A, et al. Parent's views of the importance of making changes in settings where children spend time to prevent obesity. Asia Pac J Clin Nutr. 2008;17(1):148-58. [PubMed:18364340]

9. Fulkerson JA, Kubik MY, Rydell S, Boutelle KN, Garwick A, Story $\mathrm{M}$, et al. Focus groups with working parents of school-aged children: what's needed to improve family meals? J Nutr Educ Behav. 2011;43(3):189-93. doi: 10.1016/j.jneb.2010.03.006. [PubMed: 21367663]

10. Zoellner J, Connell C, Bounds W, Crook L, Yadrick K. Nutrition literacy status and preferred nutrition communication channels among adults in the Lower Mississippi Delta. Prev Chronic Dis 2009;6(4):A128. [PubMed: 19755004]

11. Lazarus K. Nutrition practices of family physicians after education by a physician nutrition specialist. Am J Clin Nutr. 1997;65(6 Suppl):2007S-9S. [PubMed: 9174511]

12. Chelf JH, Agre P, Axelrod A, Cheney L, Cole DD, Conrad K, et al. Cancer-related patient education: an overview of the last decade of evaluation and research. Oncol Nurs Forum. 2001;28(7):1139-47. [PubMed: 11517847]

13. Battista MC, Labonte M, Menard J, Jean-Denis F, Houde G, Ardilouze JL, et al. Dietitian-coached management in combination with annual endocrinologist follow up improves global metabolic and cardiovascular health in diabetic participants after 24 months. Appl Physiol Nutr Metab. 2012;37(4):610-20. doi: 10.1139/ h2012-025. [PubMed: 22533481]

14. Turner LW, Knol L, Meyer MK. A Reaction To. Am J Health Educ. 2012;43(5):317-9. doi:10.1080/19325037.2012.10599251.
15. Noble C. Are nurses good patient educators? J Adv Nurs 1991;16(10):1185-9. doi: 10.1111/j.1365-2648.1991.tb01527.x.

16. United States Department of Agriculture Food and Nutrition Services. Healthy Hunger-Free Kids Act of 2010. 2013. Available from: http://www. fns. usda.gov/cnd/governance/legislation/cnr_2010. htm.

17. Duncan S, McPhee JC, Schluter PJ, Zinn C, Smith R, Schofield G Efficacy of a compulsory homework programme for increasing physical activity and healthy eating in children: the healthy homework pilot study. Int J Behav Nutr Phys Act. 2011;8:127. doi: 10.1186/1479-5868-8-127. [PubMed: 22085440]

18. Greening L, Harrell KT, Low AK, Fielder CE. Efficacy of a schoolbased childhood obesity intervention program in a rural southern community: TEAM Mississippi Project. Obesity (Silver Spring). 2011;19(6):1213-9. doi:10.1038/oby.2010.329. [PubMed:21233806]

19. Santos JRA. Cronbach's alpha: A tool for assessing the reliability of scales. J Extension. 1999;37(2):1-5.

20. Jaballas E, Clark-Ott D, Clasen C, Stolfi A, Urban M. Parents Perceptions of Their Children's Weight, Eating Habits, and Physical Activities at Home and at School. J Pediatr Health Care. 2011;25(5):294-301. doi:10.1016/j.pedhc.2010.05.003.

21. Fulkerson JA, Story M, Neumark-Sztainer D, Rydell S. Family meals: perceptions of benefits and challenges among parents of 8- to 10-year-old children. J Am Diet Assoc. 2008;108(4):706-9. doi: 10.1016/j.jada.2008.01.005. [PubMed: 18375230]

22. Food and Nutrition Services. WIC Program Total Participation. 2014 Available from: http://www.fns.usda.gov/pd/27wilatest.htm.

23. Food and Nutrition Services. Supplemental nutrition assistance program (SNAP) nutrition education. 2014. Available from: http:/| www.fns.usda.gov/snap/nutrition-education.

24. Ohri-Vachaspati P, Turner L, Chaloupka FJ. Elementary school participation in the United States Department of Agriculture's Team Nutrition program is associated with more healthful school lunches. J Nutr Educ Behav. 2013;45(6):733-8. doi: 10.1016/j. jneb.2012.12.006. [PubMed: 23465582]

25. Brouse CH, Wolf RL, Basch CE. School food service directors' perceptions of barriers to and strategies for improving the school food environment in the United States. Int J Health Promot Educ. 2009;47(3):88-93. doi:10.1080/14635240.2009.10708165.

26. United States Department of Agriculture. Food and Nutrition Services. Child Nutrition Programs. 2014. Available from: http://www. fns.usda.gov/tn/team-nutrition.

27. Katz DL, Katz CS, Treu JA, Reynolds J, Njike V, Walker J, et al. Teaching healthful food choices to elementary school students and their parents: the Nutrition Detectives program. J Sch Health. 2011;81(1):21-8 doi:10.1111/j.1746-1561.2010.00553.x. [PubMed: 21158862]

28. Kirks BA, Hendricks DG, Wyse BW. Parent involvement in nutrition education for primary grade students. I Nutr Educ. 1982;14(4):137-40.

29. Ollberding NJ, Wolf RL, Contento I. Food label use and its relation to dietary intake among US adults. J Am Diet Assoc. 2011;111(5 Suppl):S47-51. doi:10.1016/j.jada.2011.03.009. [PubMed: 21515135]

30. Hesse BW, Nelson DE, Kreps GL, Croyle RT, Arora NK, Rimer BK, et al. Trust and sources of health information: the impact of the Internet and its implications for health care providers: findings from the first Health Information National Trends Survey. Arch Intern Med. 2005;165(22):2618-24. doi: 10.1001/archinte.165.22.2618. [PubMed:16344419]

31. Lohse B. Facebook is an effective strategy to recruit low-income women to online nutrition education. J Nutr Educ Behav. 2013;45(1):69-76. doi: 10.1016/j.jneb.2012.06.006. [PubMed: 23305805

32. Bensley RJ, Anderson JV, Brusk JJ, Mercer N, Rivas J. Impact of internet vs traditional Special Supplemental Nutrition Program for Women, Infants, and Children nutrition education on fruit and vegetable intake. J Am Diet Assoc. 2011;111(5):749-55. doi 10.1016/j.jada.2011.02.010. [PubMed: 21515124]

33. Lieffers JR, Vance VA, Hanning RM. Use of mobile device applications in Canadian dietetic practice. Can J Diet Pract Res 2014;75(1):41-7. doi: 10.3148/75.1.2014.41. [PubMed: 24606959]

34. Abroms LC, Padmanabhan N, Thaweethai L, Phillips T. iPhone apps for smoking cessation: a content analysis. Am J Prev Med. 


\section{Scoggins R et al.}

2011;40(3):279-85. doi: 10.1016/j.amepre.2010.10.032. [PubMed: 21335258]

35. Lambert L, Raidl M, Safaii S, Conner C, Geary EJ, Ault S. Perceived Benefits and Barriers Related to Postpartum Weight Loss of Overweight/Obese Postpartum WIC Participants. Topics Clin Nutr. 2005;20(1):16-27. doi:10.1097/00008486-200501000-00003.

36. Baranowski T, Buday R, Thompson DI, Baranowski J. Playing for real: video games and stories for health-related behavior change. Am J Prev Med. 2008;34(1):74-82. doi: 10.1016/j. amepre.2007.09.027. [PubMed: 18083454]
37. Averill J. Keys to the puzzle: recognizing strengths in a rural community. Public Health Nurs. 2003;20(6):449-55. [PubMed: 14629676]

38. Brown LJ, Mitchell LJ, Williams LT, Macdonald-Wicks L, Capra S. Private practice in rural areas: an untapped opportunity for dietitians. Aust J Rural Health. 2011;19(4):191-6. doi: 10.1111/j.14401584.2011.01211.x. [PubMed:21771160]

39. Lewis LL, Kim YA, Bey JA. Teaching practices and strategies to involve inner-city parents at home and in the school. Teach Teacher Educ. 2011;27(1):221-34. 